\title{
Expansión y modernización agraria La economía santafesina durante la segunda mitad del Siglo XIX
}

\section{Agricultural expansion and modernization: The economy of Santa Fe during the second half of the nineteenth century}

\author{
Juán Luis Martirén \\ Consejo Nacional de Investigaciones Científicas y Técnicas \\ Instituto de Historia Argentina y Americana \\ "Dr. Emilio Ravignani" \\ (Argentina) \\ jlmartiren@hotmail.com
}

\begin{abstract}
Resumen
El artículo busca analizar los principales factores que promovieron la transformación radical que experimentó la economía de la provincia de Santa Fe durante la segunda mitad del siglo XIX. Luego se realiza un breve estudio de la evolución de su economía durante el período tardocolonial y postindependiente, se analizan pormenorizadamente las distintas claves del espectacular crecimiento de la producción agrícola y su impacto sobre la modernización económica. Distintas variables tales como la expansión de la colonización agrícola, la incorporación de tecnología y el incremento de la infraestructura son abordadas comparativamente con la idea de comprender mejor el peso de las mismas en el proceso de modernización. Por último, se presenta nueva evidencia sobre la modernización de los instrumentos monetarios y de crédito que se volvieron fundamentales en dicho proceso de crecimiento.
\end{abstract}

Palabras Clave: Colonización Agrícola - Modernización Económica - Mercado de crédito

MARTIREN, Juan Luis, "Expansión y modernización agraria: la economía santafesina durante la segunda mitad del siglo XIX" en Avances del Cesor, Año XI, No 11, segundo semestre 2014, pp. 135-154. 


\begin{abstract}
This paper seeks to analyze the main factors that promoted the radical transformation experienced by the Santa Fe provincial economy during the second half of the nineteenth century. After a brief analysis of the evolution of its economy during late colonial and post-independence period, we evaluate in depth the different keys of the superb growth of the agricultural production and its impact on economic modernization. Different variables such as the expansion of the colonization process, the incorporation of technology and the infrastructure investments are all comparatively analyzed to better understand their role in the modernization process. Finally, we present new evidence on the modernization of monetary and credit instruments that became essentials during the economic expansion.
\end{abstract}

Key Words: Agricultural Colonization - Economic Modernization - Credit Market

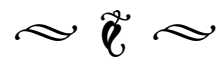

\section{Introducción}

En 1870 Pedro y José Milesi abrían un pequeño comercio en la flamante colonia Humboldt, a escasos kilómetros de Esperanza, núcleo primigenio del proceso de colonización agrícola que Santa Fe atravesaría durante la segunda mitad del siglo XIX. Nada fuera de lo común habría tenido ese evento si no fuese por el hecho de que ese emprendimiento de dos inmigrantes italianos se había transformado, poco más de una década después, en uno de los principales almacenes de ramos generales y acopio de cereales del centro oeste santafesino. En ese lapso, los hermanos Milesi habían conseguido una transformación profunda en la dinámica comercial de su empresa: las rústicas y endebles anotaciones personales que registraban las ventas al fiado sobre libretillas de mostrador se habían convertido en grandes libros contables con manejo profesionalizado, el pequeño almacén inicial se había transformado en un consistente edificio de ladrillos con grandes depósitos de granos, integrados con dos molinos harineros de avanzada tecnología, y el manejo de la información y los mecanismos de comercialización se habían adaptado e integrado al emergente mercado nacional de insumos alimenticios. ${ }^{1}$

El caso de la casa Milesi Hermanos es un excelente ejemplo de la transformación radical que la provincia de Santa Fe atravesó en su estructura socioeconómica durante la segunda mitad del siglo XIX. Si bien no puede omitirse el contexto de modernización en el que se embarcó la economía nacional (e incluso global), con las provincias del

1. El ejemplo de la Casa Milesi, de la colonia Humboldt, no sólo es importante para graficar las transformaciones económicas generales que experimentó la provincia, sino que también, por haberse conservado la totalidad del archivo privado de la misma, abre la puerta a futuras investigaciones sobre este estudio de caso, que pueden ayudar a comprender mejor la dinámica empresarial y económica provincial. Ver Museo Histórico de Humboldt, Fondo Milesi, sin clasificar. 
área pampeana a la cabeza, es indudable que Santa Fe se insertó en este proceso de manera exitosa. Si bien este proceso de fuertes cambios comienza tibiamente desde la década de 1850 , en particular durante el último cuarto del siglo la provincia alcanzó una transformación fundamental, sobre la base de una serie de variables que permitieron un crecimiento económico sin precedentes. La primera de estas, sin dudas, fue la construcción de un sólido sistema de producción cerealera en secano, que desde un reducido núcleo ubicado a escasas leguas al oeste de la ciudad capital, se fue expandiendo por toda la región central, sur y nordeste de la provincia. Con un crecimiento moderado durante las primeras décadas, la colonización consolidó su receta productiva y tecnológica desde mediados de los años 70 , y creció vertiginosamente en las décadas siguientes. Miles de hectáreas anteriormente yermas del oeste provincial o dedicadas a una ganadería de menor rendimiento -e incluso algunos nichos de producción pecuaria más capitalizada-pasaron a ser ocupadas por más de cuatrocientas colonias pobladas mayormente por inmigrantes europeos. Sin dudas, esta gran expansión no habría sido posible sin la incorporación de un parque de infraestructura moderno, que implicó la construcción de más de 3.200 kilómetros de vías férreas, modernos puertos, sistemas de telégrafos, centros de acopio, entre otros. Estas inversiones en infraestructura fueron acompañadas por numerosos cambios tecnológicos que se aplicaron sobre la economía agrícola y permitieron ampliar constantemente la escala de producción y aumentar los rendimientos del trabajo.

En forma paralela a estas transformaciones en la estructura productiva, la provincia llevó a cabo un lento pero progresivo desarrollo de un mercado de crédito y un sistema bancario moderno, que permitieron dejar atrás los arcaicos y caros mecanismos de financiación monopolizados por grandes comerciantes y bancos mercantiles tradicionales. En este contexto, emergió un dinámico grupo empresarial en diversos ámbitos de la economía; desde las colonias, aparecieron los principales brokers dedicados a los negocios inmobiliarios rurales, agroindustriales (harinas y derivados, cervecerías, destilatorios, lácteos), fabricantes de carros y maquinarias agrícolas, grandes comerciantes rurales y los principales productores rurales. En las ciudades, se conformó una elite empresaria que incluyó la readaptación de antiguos banqueros y comerciantes, y la incorporación de nuevos tipos y formas empresarias (banqueros profesionales, comerciantes, profesionales liberales, fabricantes de un amplio espectro de manufacturas, sociedades anónimas).

El presente artículo buscará abordar las distintas razones que llevaron a promover estos cambios. Más allá de la presentación de estadísticas, se pretenden analizar aquí pormenorizadamente las bases cualitativas sobre las que se asentaron el crecimiento de la producción agrícola, la evolución de las inversiones en infraestructura y el desarrollo del mercado crediticio, pilares fundamentales de la transformación de la economía local.

\section{El punto de partida: una economía en recuperación luego de la devastación postrevolucionaria}

Tanto los historiadores clásicos de la provincia como los relatos de época han coincidido en señalar, con mayor o menor 
precisión, que Santa Fe había pasado de una época de relativa bonanza a fines del período colonial a una prácticamente desesperante situación económica en las décadas que sucedieron a la revolución, marcadas por la destrucción de buena parte de su riqueza a manos de ejércitos en pugna, y por la incapacidad de contener las incursiones indígenas. ${ }^{2}$ En las últimas décadas nuevas publicaciones nos han permitido contar con hipótesis mucho mejor elaboradas y certeras sobre la situación santafesina en la etapa previa a la gran expansión, dando cuenta de la existencia de situaciones más complejas y de una periodización más acotada de los fenómenos, con coyunturas de dura crisis, pero también períodos de lenta aunque consistente recuperación, sobre todo desde mediados de la década de $1830 .^{3}$

\section{Algunos relatos de viajeros contemporáneos o de protagonistas de época en MAC CANN, William, Viaje a caballo por las provincias argentinas, Hyspamerica, Buenos Aires, 1986; PARISH, Woodbine, Buenos Ayres and the provinces of the Rio de la Plata, $2^{\text {nd }}$ Edition, John Murray, Londres, 1852; MANTEGAZZA, Paolo, Rio de la Plata e Tenerife. Viaggi e studj di... Deputato al Parlamento Italiano. Seconda edizione ritoccata ed accresciuta dall'autore, Gaetano Brigola, Milan, 1870; HEAD, Francis, Rough notes taken during some rapid journeys across the Pampas and among the Andes, John Murray, Londres, 1826; IRIONDO, Urbano de, Apuntes para la historia de la provincia de Santa Fe, Impr. de El Pueblo, Santa Fe, 1871.}

\section{TEDESCHI, Sonia, Política e instituciones en el}

Rio de la Plata, Tesis de Maestria de la Universidad Internacional de Andalucía, La Rábida, 2003; CHIARAMONTE, José, CUSSIANOVICH, Gustavo y TEDESCHI, Sonia, "Finanzas públicas y política interprovincial: Santa Fe y su dependencia de Buenos Aires en tiempos de Estanislao López", en Boletín del Instituto de Historia Argentina y Americana Dr. Emilio Ravignani, Buenos Aires, 1993, Tercera Serie, No 8; FRID, Carina, "Preludio a la Pampa Gringa", Trabajo presentado en la Red de Estudios Rurales, Instituto de Historia Argentina y Americana Dr. Emilio Ravignani, Buenos Aires, 2007; TARRAGÓ, Griselda, "Santa Fe en
Sabemos así que el funcionamiento de la economía santafesina durante el período colonial había estado sustentada tanto en aceitados circuitos mercantiles que la ciudad tenía con distintos polos productivos, cuanto en la condición de puerto preciso, que obligaba a todos los barcos que circularan por el río Paraná a registrar allí sus mercancías, otorgando una importante ventaja impositiva. ${ }^{4}$ Más allá de los sectores de subsistencia y de abasto urbano, los escasos datos disponibles muestran una economía productiva estructuralmente ligada a la costa del Paraná, constituyéndose en nexo fundamental del tráfico desde Buenos Aires hacia el Paraguay y el resto del Interior. ${ }^{5}$

Con la independencia, se supone; en principio, que la dinámica de su producción ganadera pasó a estar determinada cada vez más por la demanda atlántica. El desmembramiento de la ruta de la plata hacia el Potosí, con la consiguiente destrucción misma de la demanda de ganado mular desde ese espacio y la finalización del monopolio

el período tardo-colonial: producción ganadera, estancias y regiones" en Anuario Escuela de Historia, Rosario, 1995, Segunda época, No 17; TARRAGÓ, Griselda y BARRIERA, Darío, Nueva Historia de Santa Fe. De la autonomia a la integración. Santa Fe entre 1820 y 1853, V. V, Prohistoria, Rosario, 2006.

4. Según Álvarez, "Bajo la concesión del puerto preciso, los ingresos de Santa Fe aumentaron bastante sin que llegaran a ser considerables... No se logró sin duda hacer más fértiles las tierras, ni evitar las langostas, las sequías y las heladas; pero se consiguió transformar en troperos y pulperos a unos hombres para quienes la agricultura estaba casi vedada y la ganadería no era provechosa." En ALVAREZ, Juan, Ensayo sobre la Historia de Santa Fé, Establecimiento Tipográfico E. Malena, Buenos Aires, 1910, p. 270.

5. Ver al respecto WENTZEL, Claudia, "El comercio del Litoral de los ríos con Buenos Aires, 1821-41”, en Anuario IEHS, Tandil, 1988, pp. 161-209; TARRAGÓ, Griselda, “Santa Fe...”, Op. Cit., 1995. 
comercial español, que significó una importante transferencia de ingresos a nuevos sectores de la economía, combinados con la apertura atlántica y una sustancial rebaja en los costos del flete ultramarino, teóricamente debieron de haber beneficiado a las economías del litoral. Estas consiguieron acceder a bienes importados básicos a precios más baratos y, a su vez, pasaron a tener condiciones más ventajosas para la exportación de su principal producto, los derivados ganaderos, hacia el mercado europeo. Sin embargo, el desarrollo económico santafesino en las primeras décadas independientes tuvo problemas importantes al verse muy golpeado por las guerras civiles. ${ }^{6}$ Según testimonios de época y otros estudios tradicionales, la revolución habría afectado profundamente no sólo la estructura institucional de Santa Fe, sino también a sus bases productivas. Seis gobernadores se sucedieron entre 1810 y 1815; más allá de los problemas políticos que ello sugiere, la situación apremiante de la coyuntura bélica y la urgente necesidad de fondos, terminaron por afectar con gravedad al sector productivo, descuidándose asimismo la seguridad de sus ciudades y diezmando los stocks ganaderos. Esta dura coyuntura fue acompañada por una larga retracción comercial, que recién comenzaría a revertirse poco a poco desde

6. Es muy interesante la idea del papel de los costos de transacción y de gobernabilidad en el período postrevolucionario introducida por Eduardo Míguez. Según este autor, el costo de establecer y preservar acuerdos de gobernabilidad opacó por un buen tiempo los beneficios que los otros cambios institucionales derivados de la revolución pudieron haber logrado. Ver MÍGUEZ, Eduardo, Historia económica de la Argentina. De la Conquista a la crisis de 1930, Sudamericana, Buenos Aires, 2008, pp. 138 y ss; HORA, Roy, Historia económica de la Argentina en el siglo XIX, Siglo XXI, Buenos Aires, pp. 63-93. Ver también al respecto GARAVAGLIA, Juan Carlos, Economía, sociedad y regiones, De la Flor, Buenos Aires, 1987. la década de 1830. Desde ese momento las evidencias que resultan de la evolución de los saldos exportables, que tuvo para algunos años de la década de 1840 tasas de aumento anual comparables a las de Buenos Aires (por supuesto que la participación santafesina en volumen estaba muy lejos de la porteña), dan cuenta de una recuperación no sólo productiva, sino mercantil. ${ }^{7}$

En consecuencia, el punto de partida de la gran expansión, al promediar el siglo XIX, encuentra a la economía santafesina en un ciclo de recuperación, aunque con grandes desafíos por delante. Con el triunfo de Urquiza sobre Rosas en 1852 y la posterior creación de la nueva Confederación Argentina, parecían abrirse nuevos desafíos para las provincias del interior; de todos modos, para ese entonces Santa Fe ofrecía el escenario más paupérrimo de la cuenca del Plata. La reactivación económica de los años '40, más que un despegue, parecía ser todavía sólo una recuperación del terreno perdido, evidenciando un escenario poco comparable en términos generales con las ascendentes economías ganaderas del Litoral. En esa no tan prominente coyuntura, la elevación de Rosario al rango de principal puerto de la Confederación y la sanción de la ley de Derechos Diferenciales, que procuraba estabilizar la competencia con el puerto de Buenos Aires, parecían abrirnuevas perspectivas a futuro. ${ }^{8} \mathrm{Si}$ Rosario había comenzado a

7. Ver al respecto ROSAL, Miguel y SCHMIT, Roberto, "Comercio, mercados e integración económica en la Argentina del siglo XIX", en Cuadernos del Instituto Ravignani, Buenos Aires, 1995, No 9 ; FRID, Carina, "Preludio...", Op. Cit.

8. Ver al respecto BONAUDO, Marta y SONZOGNI, Élida, "Cuando disciplinar fue ocupar (Santa Fe, 185090)", en Mundo Agrario, Revista de estudios rurales, La 
capitalizar el mayor intercambio producto del crecimiento pecuario, la condición de puerto principal de la Confederación le permitiría consolidarse como un centro de intercambio con el interior y los mercados transatlánticos. ${ }^{9}$ La ventaja estratégica de esta ciudad portuaria no tenía mayores efectos sino principalmente en el plano comercial: si bien había permitido una reactivación de los circuitos mercantiles en torno a su Hinterland, no se vislumbraba aún una salida a los problemas estructurales que limitaban una expansión comparable a las demás provincias.

El horizonte de soluciones a esa economía constreñida parecía estar limitado a la necesidad de imitar la receta que sus vecinas del litoral habían aplicado con éxito luego de la revolución, esto es, fomentar la producción pecuaria como factor de inversión prácticamente preponderante. Se trataba de una empresa con costos relativamente bajos, que sólo imponía la necesidad de expandir el espacio productivo para consolidar las prácticas de producción pecuaria extensiva, aun cuando, lógicamente, la escasez de capital impusiera un crecimiento cuya tasa no podía apartarse de la tasa de reproducción natural del ganado. ${ }^{10}$

Plata, 2000, segundo semestre, № 1.

9. Ver, entre otros, KROEBER, Clifton, La navegación de los ríos en la historia argentina, Paidós, Buenos Aires, 1967.

10. Se intentaba seguir, sobre todo, el camino tomado por su vecina Entre Ríos, que había logrado un crecimiento pecuario muy importante en la primera mitad del siglo XIX, a partir del aprovechamiento de la abundancia de oferta de su recurso principal, la tierra, a muy bajo costo. Ello, conjugado con el fomento y el subsidio brindados por las políticas institucionales provinciales, habían empujado a Entre Ríos a secundar a Buenos Aires en producción ganadera en el área pampeana. Ver SCHMIT, Roberto, Historia del capitalismo agrario pampeano, T.

V. Los límites del progreso: expansión rural en los orígenes del capitalismo rioplatense, Siglo XXI-Universidad de
Si la consolidación portuaria de Rosario ponía en evidencia estas ventajas, la región central santafesina, por su parte, se encontraba en una encrucijada particularmente compleja en el preludio a su gran expansión agrícola, y nada en aquélla hubiera podido anticipar a ésta. Sólo la expansión sobre las fronteras, un punto en el cual, por lo demás, toda la élite política y económica santafesina concordaba en priorizar, constituía un camino claro, más allá de todos los demás proyectos.

El punto de partida de la gran expansión tenía entonces importantes cuellos de botella que debían ser solucionados, sobre todo para el Hinterland de la ciudad capital. $\mathrm{La}$ disponibilidad de tierras yermas era abundante, aunque la imposibilidad de brindar seguridad para su producción, sumada a la escasez apremiante de mano de obra y capital, desequilibraban la composición de cualquier tipo de una ecuación factorial que permitiese el desarrollo económico. Como veremos a continuación, esos problemas fueron encontrando una lenta, pero progresiva solución a partir del crecimiento del área colonizada de la región central y del desarrollo de una dinámica ganadería ovina y vacuna en el sur provincial.

\section{Los pilares de la modernización económica y productiva}

\section{Tierras, Inmigración y \\ colonización agrícola}

La agricultura tradicional santafesina, que de todos modos había logrado algunos

Belgrano, Buenos Aires, 2008, pp. 27 y ss. 
avances durante la primera mitad del siglo XIX, sólo muy lentamente y luchando contra muchos factores hubiera podido alcanzar aumentos de productividad que la pusieran en tren de crecimiento, al menos a la par de la más dinámica ganadería. La introducción de un elemento de ruptura se convertía así en una necesidad imprescindible para el ensayo y la puesta a punto de una nueva ecuación económica, centrada en la agricultura como factor de generación de valor. ${ }^{11}$ En ese contexto, la colonización agrícola con inmigrantes extranjeros que pudiesen ocupar y poner en producción las tierras de frontera, se planteaba como una posible solución a este problema estructural. Los experimentos iniciales de colonización, emplazados en la segunda mitad de la década de 1850, parecieron ser en un primer momento la punta de lanza de un ciclo que se extendería rápidamente, ya que los contratos de colonización firmados entre empresarios privados y la provincia proliferaron con rapidez. ${ }^{12}$ De todos modos, pronto se vio que se trataba de un negocio de alto riesgo y que ofrecía ganancias -si las había - sólo a mediano o largo plazo. Así, las colonias primigenias debieron luchar por no desaparecer durante sus primeros diez años de existencia. Recién con el auge de la demanda de cereales que produjo la Guerra del Paraguay, este espacio comenzó un ciclo de importante expansión. La región acaparó una gran masa de dinero circulante que terminó por crear un nuevo clima de negocios,

11. DJENDEREDJIAN, Julio, BEARZOTTI, Silcora y MARTIREN, Juan, Historia del Capitalismo Agrario Pampeano. Expansión agrícola y colonización en la segunda mitad del siglo XIX, T. I y II, Teseo, Buenos Aires, 2010.

12. Todos los contratos firmados con el Gobierno Provincial pueden verse en Archivo General de la Provincia de Santa Fe (en adelante AGPSF), Escribanos, Escribanía de Gobierno, Años 1853-1857. sobre todo en el plano inmobiliario. De este modo, desde 1866 algunos empresarios o bien colonos devenidos en brokers inmobiliarios comenzaron a planificar el establecimiento de nuevas colonias, en tierras circundantes a las primigenias. En consecuencia, aparecieron las primeras colonias satélite de ese núcleo, que para mediados de la década de 1870 iniciaría su primera expansión hacia el oeste provincial. ${ }^{13}$

En esencia, el auge propulsado por la guerra cambió la lógica misma de la colonización: a partir de allí la expansión de las colonias satélite pasó a sustentarse sobre una demanda genuina de terrenos, no teniendo que invertir los empresarios porciones de capital en la atracción de inmigrantes. Surgió a la sazón un contexto cualitativamente diferente del de los años anteriores: el crecimiento de la dimensión misma del fenómeno colonizador, marcado por el aumento poblacional y la progresiva ocupación del espacio, comenzaría a posibilitar entonces soluciones reales a los antiguos problemas de aislamiento, dificultades de comercialización y acceso a los mercados. El mismo planeamiento

13. El proceso de colonización agrícola santafesino cuenta con una vasta y excelente bibliografía -tanto en el ámbito académico como en el campo de la difusión-, basada sobre todo en la rica estadística que se ha conservado sobre el fenómeno, como también en la amplia panoplia de obras de época y publicaciones periódicas de las cuales puede extraerse tanto información cuantitativa como datos testimoniales de inusitada riqueza informativa. Solo por citar algunos, ver: GALLO, Ezequiel, La Pampa Gringa, Sudamericana, Buenos Aires, 1983; BONAUDO, Marta, "La organización productiva y política del territorio provincial (18531912)", en Barriera, Darío (director) Nueva historia de Santa Fe, T. VI, Prohistoria Ediciones, Rosario, 2006; DJENDEREDJIAN, Julio, BEARZOTTI, Silcora y MARTIREN, Juan, Historia ..., Op. Cit.; GORI, Gastón, Inmigración y colonización en la Argentina, EUDEBA, Buenos Aires, 1964. 
de la explotación y la ecuación de costos y beneficios de los productores comenzarían a cambiar. Se podría por fin pensar en encarar una mayor especialización productiva en torno a los cereales más demandados por las grandes urbes, ya que por primera vez era posible efectuar economías de escala significativas en el transporte de la producción hacia los puntos de embarque fluvial. ${ }^{14}$ Por lo tanto, si el crecimiento del fenómeno había estado limitado a las tres colonias primigenias, desde 1866 su evolución adquiriría una intensidad hasta el momento impensada: en tan sólo siete años la cantidad de colonias poco más que se decuplicaría, el crecimiento demográfico se multiplicaría por cuatro y la extensión cultivada con trigo aumentaría en más de veinte veces. ${ }^{15}$

Paralelamente al conflicto bélico, otro factor clave en la expansión del fenómeno colonizador, particularmente desde 1870, fue la puesta en marcha del Ferrocarril Central Argentino, que unía la ciudad de Rosario con la de Córdoba. ${ }^{16} \mathrm{~A}$ partir de 1870 se fueron

14. MARTIREN, Juan, "La mies madura. Colonización agrícola y crecimiento económico en Santa Fe durante la segunda mitad del siglo XIX”, Tesis doctoral, Universidad Nacional del Centro de la Provincia de Buenos Aires, Tandil, 2013, Cap. IV.

15. Por cuestiones de espacio, no se han expuesto datos sobre el crecimiento cuantitativo de las distintas variables de la colonización. Sobre este aspecto, pueden consultarse la variedad de estadísticas dispuestas en los siguientes trabajos: GALLO, Ezequiel, La Pampa..., Op. Cit., BONAUDO, Marta y SONZOGNI, Elida, CRAGNOLINO, Silvia y ALBAIZETA, María, "Ferrocarriles y mercado de tierras en el centro-sur de Santa Fe (1870-1900)", en Siglo XIX, Monterrey, 1993, № 6 ; DJENDEREDJIAN, Julio y otros, Expansión.., Op. Cit.

16. Una impresión de época sobre la importancia y las ventajas que traería la construcción del Ferrocarril Central Argentino puede verse en El Ferrocarril, Rosario, $13 / 09 / 1864$ creando, a lo largo de la línea y partiendo desde las cercanías de Rosario, las colonias de Bernstadt, Carcarañá, San Jerónimo del Sur, Cañada de Gómez y Tortugas, completadas años más tarde con las de Wheelwright y Armstrong, al subdividirse tierras situadas entre las anteriores.

Si los años '70 se convirtieron en un período bisagra para la transformación de la agricultura, la etapa abierta desde la década siguiente marcaría un antes y un después en la economía agraria santafesina. Varias razones generales explican este fenómeno: el fin de la lucha de fronteras, la consolidación definitiva del Estado nacional, la adopción de un nuevo régimen monetario, el acceso masivo de la producción agrícola argentina al mercado mundial, sostenidos precios internacionales de los granos y creciente y generalizada inversión de capital. En materia de colonización, los números serían simplemente sorprendentes: en poco más de una década, la provincia superaría el millón de hectáreas sembradas y la cantidad de colonias alcanzaría las cuatro centenas. La definitiva anexión de una vasta franja de tierras en la zona occidental de la provincia permitiría la consolidación del fenómeno. De todos modos, ese corrimiento hacia el oeste, a la vez que tendría un progresivo y constante crecimiento, iría planteando nuevos desafíos que debían resolverse sobre la marcha: alargamiento de las vías de comunicación, ampliación de la escala de los establecimientos, resolución de los problemas vinculados a una agronomía de características muy distintas de las correspondientes en las áreas más antiguas. Se comenzarían a remover así antiguos problemas, capitalizándose la experiencia previa y promoviéndose una serie de inversiones en infraestructura que 
permitirían una rápida expansión de la agricultura especializada orientada hacia el mercado externo sobre territorios más alejados de los grandes centros de acopio.

Sería tal el crecimiento, que la colonización pasaría a trascender las especificidades regionales, abarcando de ese modo a la gran mayoría del territorio cultivable en la provincia. Con excepción de algunos núcleos ganaderos del dinámico sur provincial, la subdivisión de la tierra para agricultura especializada alcanzaría tanto a grandes propiedades fundiarias que se habían enajenado luego de la expansión de fronteras, cuanto a muchas estancias que ya no podían competir en términos de rentabilidad con la producción cerealera. La colonización agrícola había consolidado, transformando y modernizando por completo la economía santafesina. Aunque para hacerlo, requirió el desarrollo de variables paralelas sin las cuales habría sido imposible su expansión.

\section{La modernización de la infraestructura}

A lo largo de la década de 1870, la producción triguera santafesina-que para ese entonces se había convertido en el principal motor de su economía y a su vez se encontraba en franco recorrido hacia la especializacióniría invadiendo poco a poco el mercado de abasto de Buenos Aires, consiguiendo incluso posicionarse como una gran competidora de los cereales importados y generando eventualmente excedentes exportables, al menos desde 1879. Sería justamente a partir de ese año que el país abandonaría su histórica condición de importador neto de granos, para dar lugar a una nueva etapa de espectacular crecimiento de los saldos exportables en materia cerealera. Dicho fenómeno, que había comenzado con los novedosos y al mismo tiempo arriesgados experimentos de la década de 1850, se había tornado luego de la guerra del Paraguay una alternativa seria a la tradicional estructura ganadera santafesina, y pasaba a captar los mercados hasta entonces en manos de los proveedores extranjeros de cereales y farináceos. Con la paulatina mejora en eficiencia y operatividad que las colonias habían experimentando desde ese momento, la desventaja que los altos costos de transporte en el interior les propinaban para competir con los productos extranjeros, se iría desvaneciendo.

Todo este proceso, que se consolidaría en los '80 y '90, fue a la vez parte y resultado de profundos cambios en la economía de la provincia en general. En ese marco, la especialización triguera constituyó una base imprescindible, en tanto proveyó economías de escala y permitió la formación de un mercado nacional de cereales en el que Santa Fe tomaría parte principal, fomentando por un lado la difusión y ampliación de una moderna red de comunicaciones ferroviaria, fluvial y terrestre, la creación de centros de acopio e infraestructura portuaria y el fomento de emprendimientos industriales, de producción y de servicios.

De este modo, al igual que en las áreas específicas de colonización agrícola, los números de la economía en general de la provincia reflejaron este crecimiento. ${ }^{17}$ Las

17. Ya en 1881, al analizar la evolución de las rentas fiscales, Gabriel Carrasco remarcaba que estos cambios se habían hecho evidentes: "Si en 1860 toda la renta pública de esta provincia apenas alcanzaba a 60.000 pesos fuertes, y hoy ella pasa de medio millón, resulta que se ha octuplicado la renta privada, cuyo conjunto constituye la pública... Pero, ¿a qué se deben tan asombrosos adelantos? Causas múltiples y complejas son las que los han originado, pero, especialmente la gran cantidad de inmigración entrada en la Provincia, su sistema de 


\section{Cuadro No 1 - Evolución de la riqueza provincial per cápita por quinquenio entre 1863 y 1891 , en pesos oro}

\begin{tabular}{lccc}
\hline & $\begin{array}{c}\text { Riqueza (en millones } \\
\text { de \$oro) }\end{array}$ & Habitantes & $\begin{array}{c}\text { Riqueza per cápita } \\
\text { (en \$oro) }\end{array}$ \\
\hline $\mathbf{1 8 6 3 - 6 7}$ & 32 & 73.000 & 440 \\
$\mathbf{1 8 6 8 - 7 2}$ & 50 & 97.000 & 515 \\
$\mathbf{1 8 7 3 - 7 7}$ & 69 & 140.000 & 491 \\
$\mathbf{1 8 7 8 - 8 2}$ & 98 & 180.000 & 540 \\
$\mathbf{1 8 8 3}$ & 119 & 190.000 & 626 \\
$\mathbf{1 8 9 1}$ & 188,2 & 300.000 & 627 \\
\hline
\end{tabular}

Fuente: Elaboración propia en base a MULHALL, Michael y MULHALL, Edward, Handbook of the River Plate comprising the Argentine Republic, Uruguay, and Paraguay... Fifth Edition, Trübner and Co., London, 1885, p. 403; MULHALL, Michael y MULHALL, Edward, Handbook of the River Plate comprising the Argentine Republic, Uruguay, and Paraguay. Sixth Edition, Kegan Paul, Trench \& Co., London, 1892, pp. 374-6

estadísticas al respecto en los años subsiguientes serían todavía más espectaculares. Santa Fe no sólo crecería demográficamente, sino que paralelamente la ampliación de esos flujos inmigratorios impactaría de lleno en la creación de riqueza local. Algunas estimaciones sobre la evolución del crecimiento de la riqueza general de la provincia ayudan a tener una impresión más clara de este fenómeno.

Si bien las cifras transcriptas en el cuadro precedente son estimaciones muy generales, permiten tener de todos modos una impresión suficiente de la progresión y el peso de la

colonización, las leyes liberales respecto a la propiedad territorial y el desarrollo de vías de comunicación." CARRASCO, Gabriel, Datos estadísticos de la Provincia de Santa Fe, Imprenta de E. Carrasco, Rosario, 1881, pp. 15-17. modernización económica provincial hasta la década de 1890. En consecuencia, puede notarse que la riqueza total (en este caso el cálculo de Mulhall incluye a las tierras, construcciones, ganado y otros bienes muebles) se sextuplicó en tan sólo treinta años, teniendo la economía provincial un ritmo de acumulación de riqueza anual entre 1863 y 1891 de prácticamente un 21\%. En cuanto al crecimiento de la riqueza per cápita, los ritmos fueron también espectaculares, aun dada la magnitud del crecimiento demográfico, asimilando el caso a los de más rápido crecimiento en el mundo moderno. Una expansión del 1,42 veces entre 1863 y 1883, más el mantenimiento de la media de riqueza hacia 1891 luego de un crecimiento de la población de más del 33\% en sólo ocho años, 
son cifras no menos que importantes. El trigo en este aspecto tuvo un rol fundamental: el área sembrada con este cereal pasó de escasísimas 1.600 hectáreas en 1865 a más de un millón en 1895; el lino, cultivo prácticamente inexistente antes de 1880, pasó a tener sementeras por 266.000 hectáreas y el cultivo del maíz superó las 185.000 hectáreas ese mismo año. ${ }^{18}$

Este frenético crecimiento de la riqueza y de la producción, no habría sido posible sin la emergencia de un moderno sistema de infraestructuras que consolidaran la integración del mercado de granos. En este sentido, si tradicionalmente el transporte fluvial había tenido un aceptable desarrollo en Santa Fe, la expansión de las praderas cerealeras hacia áreas más alejadas de los principales puntos de exportación requería fundamentalmente, por un lado, de un amplio tendido ferroviario imprescindible para lograr movilizar y administrar los crecientes volúmenes de mercancías que significaban las cosechas excedentes y, por otro, de una importante infraestructura de acopio y carga en los puertos. Esta fue una preocupación fundamental desde fines de los '70, y si bien la falta de ferrocarriles hasta ese entonces no había sido un impedimento para el desarrollo del principal núcleo de colonias ubicado en el Hinterland de la ciudad de Santa Fe, sí se volvía un estorbo para el adelanto de la colonización en zonas más alejadas, esto es, hacia el oeste provincial. ${ }^{19}$ En este sentido, las quejas por

18. MULHALL, Michael y MULHALL, Edward, Handbook of the River Plate comprising the Argentine Republic, Uruguay, and Paraguay. Sixth Edition, London, Kegan Paul, Trench \& Co., 1892, p. 374; HOTSCHEWER, Curto, Evolución de la agricultura en la provincia de Santa Fe, Imp. de la Provincia, Santa Fe, 1953, pp. 119 y ss.

19. Nos referimos puntualmente a los territorios de problemas puntuales de falta de medios de comunicación y alto costo de los servicios de transporte siguieron repitiéndose en años sucesivos, en buena parte porque, dados los rápidos avances de la superficie cultivada, era difícil lograr que la infraestructura de comunicaciones los siguiera de cerca. ${ }^{20}$

No obstante, desde mediados de la década de 1880 estos problemas comenzaron a quedar atrás, a partir del impresionante desarrollo que adquirió el sistema ferroviario, impulsado tanto desde el ámbito público como desde el privado.

Tal como se desprende de este cuadro (ver Cuadro No 2), en 1870 sólo 114 kilómetros de vías férreas atravesaban la provincia de Santa Fe; se trataba del primer ferrocarril de magnitud construido en la República Argentina, el Central Argentino, que unía las ciudades de Rosario y Córdoba. Este ferrocarril, como mencionamos antes, tuvo una importancia fundamental en el desarrollo y dinámica de la economía del Hinterland de la ciudad de Rosario, promoviendo la ganadería ovina y el surgimiento de un nuevo núcleo de colonización hacia inicios de esa década. Sin embargo, y a pesar de haber existido varios

lo que posteriormente serían los departamentos de Castellanos, San Cristóbal, San Martín, Belgrano y Caseros, distritos emblemáticos de la especialización triguera extensiva, en los que la presencia del ferrocarril se volvió fundamental.

20. Ver por ejemplo el informe de inspección agrícola en Rosario, marzo de 1884, en REPUBLICA ARGENTINA, DEPARTAMENTO NACIONAL DE AGRICULTURA, Boletin del Departamento Nacional de Agricultura, T. VIII, pp. 247/8; también PEYRET, Alejo, Una visita á las colonias de la Republica Argentina por Alejo Peyret, Imprenta “Tribuna Nacional”, Buenos Aires, 1889, T. I, p. 4; y La Agricultura, Buenos Aires, T. I, No. 2, 12/01/1893, p. 17. 


\section{Cuadro No 2 - Evolución del tendido ferro- viario en la Provincia de Santa Fe entre 1870 y 1894, en kilómetros.}

\begin{tabular}{lccc}
\hline & \multicolumn{3}{c}{ Año } \\
\cline { 2 - 4 } & $\mathbf{1 8 7 0}$ & $\mathbf{1 8 8 7}$ & $\mathbf{1 8 9 4}$ \\
\hline Particulares & 114 & 711 & 2.076 \\
Estatales & 0 & 596 & 1.207 \\
Total & $\mathbf{1 1 4}$ & $\mathbf{1 . 3 0 7}$ & 3.283 \\
\hline
\end{tabular}

Fuente: Elaboración propia en base a CARRASCO, Gabriel, La provincia de Santa Fé. Revista de su estado actual y de los progresos realizados, Coni, Buenos Aires, 1888, p. 50 y CARRASCO, Gabriel, Intereses nacionales de la República Argentina; estudios sobre población, colonización, agricultura..., J. Peuser, Buenos Aires, 1896, p. 243

proyectos ferroviarios durante la década de 1870, este emprendimiento no se replicó sino recién en el primer lustro de los'80. A partir de ese momento el impulso del Ferrocarril Oeste Santafesino -que unió la ciudad de Rosario con la colonia Candelaria a fines de 1883- el tan esperado ferrocarril a las colonias del oeste -cuyo acto inaugural sería el 1 de enero de 1885 con su llegada a Esperanza- habían sentado las bases del singular desarrollo posterior. Para 1887, el tendido férreo se había vuelto 11,5 veces mayor que en 1870 y ya a mediados de la década de 1890 dicha cantidad de kilómetros de rieles poco menos que se había triplicado en tan sólo siete años. ${ }^{21}$

Ese desarrollo ferroviario, a la vez que consolidó a los distritos del oeste provincial -con tierras más baratas y unidades de producción más extensas- como los principales núcleos productores de trigo y lino, permitió al mismo tiempo expandir el desarrollo portuario de las principales ciudades ribereñas del Paraná. ${ }^{22}$ Rosario, cuya presencia en la economía provincial ya era notoria como hemos visto desde tiempos de la Confederación urquicista, terminó posicionándose como el segundo centro de exportación del país. ${ }^{23}$ Con un crecimiento en infraestructura muy notable, pudo aprovechar además las particulares características de su puerto, que por las altas riberas del río posibilitaba la carga de buques con bienes de gran volumen en condiciones muy cómodas, lo

21. Al respecto ver HOTSCHEWER, Curto, Evolución..., Op. Cit., p. 105 y ss; GALLO, Ezequiel, La Pampa..., Op. Cit., p. 232 y ss; DJENDEREDJIAN, Julio, BEARZOTTI, Silcora y MARTIREN, Juan, Historia..., Op. Cit.; sobre el Ferrocarril Oeste Santafesino, ver DALLA CORTE, Gabriela, Lealtades firmes. Redes de sociabilidad y empresas: La "Carlos Casado SA" entre la Argentina y el Chaco Paraguayo (1860-

1940), Consejo Superior de Investigaciones Científicas, Barcelona, 2009.

22. Los principales centros portuarios de exportación en Santa Fe desde 1880 pasaron a ser Rosario, Santa Fe, Coronda, Villa Constitución, San Lorenzo y Helvecia. Sobre puertos y fondeaderos en Santa Fe, ver CARRASCO, Gabriel, La provincia de Santa Fe. Su colonización agrícola, Buenos Aires, Imprenta Helvetia, 1894, p. 82.

23. Sobre el desarrollo del mercado inmobiliario y de la red ferroviaria en el Hinterland rosarino, ver BONAUDO, Marta y SONZOGNI, Elida, CRAGNOLINO, Silvia y ALBAIZETA, María, "Ferrocarriles...", Op. Cit. 
que le permitía operar grandes cantidades de granos. ${ }^{24}$ Para 1881 el puerto rosarino contaba con una infraestructura moderna para limpieza, clasificación y preparación del grano para exportar, aunque es verdad que bien pronto la misma se vería continuamente sobrepasada por el aumento espectacular de los envíos. ${ }^{25}$ Más allá de esos problemas, es realmente sorprendente que esa infraestructura haya seguido con relativa eficacia el impresionante aumento de los saldos exportables, habida cuenta de la complejidad del transporte de bienes de gran volumen como el trigo, hacia destinos de alta selectividad como los europeos. ${ }^{26}$

Otro de los factores derivados de esta especialización cerealera fue la expansión de

24. La evolución de la carga transportada en el puerto de Rosario entre 1857 y 1895 es simplemente asombrosa: pasó de transportar 20.000 toneladas en 1857, a 1.048 .515 en 1887 y a 1.611 .975 en 1895 . Ver cifras en CARRASCO, Gabriel, Intereses nacionales de la República Argentina; estudios sobre población, colonización, agricultura..., J. Peuser, Buenos Aires, 1896, p. 267. Debe destacarse no obstante que para 1879, el trigo ya constituía más del $30 \%$ del valor de las exportaciones al extranjero desde el puerto de Rosario. REPÚBLICA ARGENTINA, DEPARTAMENTO NACIONAL DE AGRICULTURA, Boletín del Departamento Nacional de Agricultura, Buenos Aires, T. IV, p. 112.

25. Kaerger en 1896 destacaba que si bien existían grandes centros de acopio, graneros y elevadores, el sistema no conseguía sostener el ritmo de crecimiento en el volumen de las cosechas de trigo. Ver KAERGER, Karl, La agricultura y la colonización en Hispanoamérica. Los estados del Plata, Academia Nacional de la Historia, Buenos Aires, 2004, pp. 230-231.

26. Vale destacar que algunos autores tienen una visión negativa sobre este aspecto, a partir de la cual remarcan que la provincia -y región pampeana en general- no pudieron acompañar con infraestructura acorde, el gran desarrollo de la producción granaria. Tal vez el precursor de estos planteos haya sido SCOBIE, James, Revolución en las Pampas, Solar/Hachette, Buenos Aires, 1968. una serie de emprendimientos industriales, entre los que se destacaron diferencialmente los molinos harineros. ${ }^{27} \mathrm{La}$ fabricación de harina había comenzado como una actividad con perspectivas a futuro ya mediados de los'60 en las colonias de Esperanza y San Carlos, aunque se trataba todavía más bien de atahonas tradicionales a fuerza animal, y de algunos molinos de viento e hidráulicos, la mayoría con escasa capacidad de molienda y no aptos para lograr una harina de gran calidad, susceptible de exportación. El cambio empezará a notarse en los primeros años de la década de 1870, cuando comenzaron a proliferar los molinos a vapor en el Hinterland de Santa Fe. Para 1872 existían quince molinos en las distintas colonias de Santa Fe, de los cuales cuatro estaban en Esperanza y tres en San Carlos; ese año habían logrado igualar en número a las atahonas. ${ }^{28} \mathrm{La}$ progresión fue constante: para 1880 existían ya 39 molinos a vapor, y 43 en 1882, con una fuerza motriz en conjunto de 600 caballos de fuerza y una producción diaria de alrededor de 2.000 bolsas de harina de 8 arrobas. ${ }^{29}$

27. Con algo de orgullo por los logros realizados con la colonización, en 1888 Carrasco afirmaba: "Hasta 1860 el pan que se comía en Santa Fe, era elaborado casi en su totalidad con harinas de otras provincias y hasta de Chile y California! En 1887, la producción de trigo en esta Provincia ha subido a cuatrocientos setenta y siete millones de kilogramos y existen 3 molinos a sangre, 4 a agua y 63 a vapor, con una fuerza de 1.664 caballos". CARRASCO, Gabriel, La Provincia..., Op. Cit., p. 109.

28. WILCKEN, Guillermo, Las colonias. Informe sobre el estado actual de las colonias agricolas de la República Argentina presentado a la Comisión Central de Inmigración por el Inspector Nacional de ellas. 1872, Buenos Aires, Sociedad Anónima, 1873, Apéndice Estadístico.

29. El dato de 1880 en el informe de ARAGÓN, Agustín, Informe de la Inspección de Colonias de la Provincia de Santa-Fé hasta 1880, Imprenta de R. Carrasco, Rosario, 1881, p. 8; los de 1882 en AGPSF, Gobierno, Notas, T.CVII, 1882-3, leg. 10. 
Desde la década de 1880, a la vez que la cantidad de molinos aumentaba, también cambiaba su tecnología. Estaba claro que para competir en el difícil mercado europeo, se necesitaba lograr estándares de calidad que sólo podían alcanzarse con sistemas de molienda avanzados. Así, iría dándose un reemplazo paulatino de los sistemas por otros más modernos, en especial los nuevos de cilindros y con tracción a vapor, cuestión que se reflejaría en el nivel de inversión de capital por establecimiento más que en el nivel de concentración de la industria, ya que en realidad el número de establecimientos aumentaría en vez de disminuir. Puede notarse que ya para 1887, de los 70 molinos existentes; quedaban sólo tres con tracción a sangre, lo que da cuenta de un nivel de perfeccionamiento técnico acorde al volumen de producción y a las exigencias del mercado internacional de cereales. ${ }^{30}$

Por lo demás, si la colonización había resultado el más evidente factor de cambio productivo y la ganadería había comenzado a perder peso en los prolegómenos del siglo, no por eso debe omitirse su incidencia en la economía provincial. Entre otros aspectos, es necesario destacar la expansión de la ganadería ovina moderna en el sur provincial, que ya en la década del '70 había ido desalojando a la menos rentable ganadería vacuna criolla de las áreas de antigua ocupación, y se había posicionado como un importante expediente de inversión, también impulsada por el

30. Sobre la incorporación de tecnología y la evolución de la producción en los molinos harineros santafesinos, ver FERNANDEZ, Sandra, Burgueses y empresarios. La ciudad de Rosario y el espacio rural en el cambio de siglo, 1880-1914, Tesis de Maestría en Ciencias Sociales, FLACSO, Buenos Aires, mimeo, 1999. proceso de modernización de la economía. La caída en las cifras de producción ganadera no debe entonces considerarse como una simple pérdida, sino más bien como una readecuación del sistema de producción agropecuario imperante: había quedado claro que, con algunas excepciones, la producción agrícola se volvía una opción mucho más atractiva, no sólo debido al contexto de alta demanda de tierras por causa del aumento de los flujos inmigratorios, sino también porque otorgar la tierra en arrendamiento implicaba tomar menores riesgos. Y, sobre todo, porque Santa Fe se había posicionado en el rubro dominando el hito tecnológico de la producción cerealera sobre tierras nuevas, cosa que en ninguna otra provincia habían podido desarrollar antes. No tenía por tanto competencia, mientras que las incursiones en el ganado lanar o en el vacuno debían enfrentar a sus similares de Córdoba, Entre Ríos o Buenos Aires, a menudo mejor dotados para ese tipo de producción, o que ya habían avanzado en el dominio de sus sutilezas técnicas desde mucho antes.

\section{La transformación de los instrumentos financieros y monetarios. $\mathrm{El}$ mercado de crédito}

La modernización financiera de la economía provincial durante los '80 fue otra de las variables clave que ayudan a comprender el fenomenal ciclo de crecimiento económico. Desde los '70, Santa Fe consiguió -con algunas dificultades- estabilizar sus relaciones con el poder central, y fue construyendo progresivamente una administración más sólida, a partir sobre todo de recursos financieros 
genuinos. ${ }^{31}$ Esa mayor estabilidad institucional no impidió la persistencia de la inseguridad de bienes y personas en el medio rural, pero fue uno de los elementos que a mediano plazo habrían de lograr reducirla significativamente. En el marco de esa coyuntura, la economía y la sociedad provincial fueron contorneando una transformación que también se vería reflejada en el plano financiero ya desde la segunda mitad de los '70. La expansión de las fronteras y el avance de la colonización habían adquirido un ritmo tal que, sin una economía moderna y dinámica, donde el costo del dinero y el crédito se adecuaran a sus necesidades, dichos niveles de crecimiento serían insostenibles. En ese contexto, la necesidad de crear un sistema bancario moderno se volvió fundamental; debían reemplazarse los antiguos bancos mercantiles, generalmente constituidos por comerciantes o empresarios particulares, que respaldaban su capacidad financiera mediante recursos diversos, entre los cuales se encontraba incluso la emisión de moneda. En este tipo de instituciones financieras reinaba el cortoplacismo en la colocación de créditos, que generalmente se hacía a tasas muy elevadas, dada la alta exposición al riesgo de esos operadores, que no contaban con el respaldo de prestamistas de última instancia. ${ }^{32}$

31. Análisis muy completos sobre el funcionamiento del sistema político provincial en GALLO, Ezequiel, Colonos en armas: Las revoluciones radicales en la provincia de Santa Fe (1893), Editorial del Instituto, Buenos Aires, 1977; BONAUDO, Marta y SONZOGNI, "Los caminos de construcción de un orden capitalista: Fracciones burguesas y Estado en Santa Fe (1850-1900)", en Historia Regional, Villa Constitución, 2001, Sección Historia (ISP No 3), № 19.

32. No es extraño encontrar, en tal sentido, que funcionarios provinciales llamasen la atención sobre esta problemática, tan temprano como en 1872: "Mientras no se funden en esta Provincia establecimientos bancarios que giren un gran capital, su marcha progresista tendrá
$\mathrm{Si}$ bien desde mediados de los '60 comenzaron a aparecer algunos bancos de mayores dimensiones en Rosario, todavía hasta el primer lustro de 1870 las tradicionales instituciones de crédito mercantil tenían un lugar muy destacado. Recién a partir de ese momento comenzaron a dejar paso a bancos por acciones, de mucho mayor capital, que centraban su capacidad de préstamo en la captación de depósitos y en la financiación extrarregional. ${ }^{33}$ Así, para 1875, ya consolidaron su presencia en Rosario y Santa $\mathrm{Fe}$ tres de las mayores instituciones bancarias provinciales: el Banco Provincial de Santa Fe y el Banco Nacional, ambas públicas, y el Banco de Londres y Río de la Plata, de mayoría accionaria británica. ${ }^{34} \mathrm{~A}$ partir de entonces, la oferta de crédito se fue concentrando en esos bancos más sólidos, respaldados por un fuerte capital, y que pronto constituyeron carteras de depósitos considerables. Los comerciantes continuaron su rol financiero, pero ahora en gran medida como intermediarios entre esos grandes bancos y los productores y tomadores

siempre por rémora la falta de moneda para todos los negocios." LARGUIA, Jonas, Memoria presentada al Excmo. Gobierno de la Provincia de Santa Fe por el Inspector de Colonias, Imprenta del Fénix, Santa Fe, 1872, p. 22.

33. DE LA FUENTE, Diego, CARRASCO, Gabriel y MARTINEZ Alberto (directores) Segundo censo de la República Argentina. Mayo 10 de 1895, Taller Tipográfico de la Penitenciaría Nacional, Buenos Aires, 1898, T. III, p. 146.

34. Es de destacar que el Banco de Londres y Río de la Plata ya operaba en la provincia desde los años' 60 . Con la aparición en escena de los dos grandes bancos estatales, más el Banco de Londres, la situación bancaria santafesina tendría un punto de inflexión. Sobre el desarrollo de las instituciones bancarias en Santa Fe, ver ENSINCK, Oscar, "Moneda y Bancos en la Provincia de Santa Fe", Separata del tomo III de la Historia de las Instituciones de la Provincia de Santa Fe, Santa Fe, 1970, pp. 235-292. 
de menor dimensión, además de concentrarse en el crédito hipotecario, como veremos pronto.

Ya a mediados de los'80, con el proceso de colonización consolidado y el gran crecimiento de las inversiones en infraestructura, que implicaron fuertes entradas de capitales extranjeros, la expansión del sistema bancario se volvió apabullante. Entre 1885 y 1890 el número de bancos que operaba en la provincia pasó de 8 a 30, y su capital total de 5 a 25 millones de pesos oro. ${ }^{35}$ Esa expansión se dio simultáneamente en términos geográficos y socioeconómicos; ello se reflejó particularmente en la gran difusión de sucursales bancarias situadas en las colonias. Por ejemplo, Esperanza contó con una sucursal del Banco Nacional desde 1884, y para 1892 incluso con una casa bancaria propia, el Banco Comercial de las Colonias; Rafaela tuvo una sucursal del Banco Provincial desde 1887, al igual que Gálvez, Reconquista, Casilda, Ocampo y Coronda; San Carlos y Cañada de Gómez contarían con otras del Banco Nacional desde 1886.

Paralelamente a las instituciones bancarias, el mercado de crédito informal, con existencia de larga data en la provincia, también tuvo un papel muy importante hasta entrados los años '80, alimentado por prestamistas particulares, que otorgaban dinero a crédito con base en garantías hipotecarias. $\mathrm{Y}$ su importancia continuó después, dado que no competía, sino que se complementaba con el sistema bancario formal. ${ }^{36}$ Las redes de crédito

35. CARRASCO, Gabriel, Juicio Estadístico de la Administración del Dr. José Gálvez (1886-1890), Tip. y Enc. Nueva Época, Santa Fe, 1897, p. 50.

36. Debe remarcarse que si bien estos préstamos tenían 150 informal, vinculadas por lo general a comercios de campaña o de pueblos, diseminaban entre los productores los fondos recibidos de prestadores formales y de las casas comerciales de las ciudades principales, o bien simplemente se trataba de actores que entregaban a crédito sus rentas particulares o ahorros y excedentes transitorios o permanentes, producto de herencias recibidas. Este tipo de préstamos fueron los que alimentaron la financiación privada en las colonias, aunque también tuvieron un peso importante en las plazas urbanas de la provincia. ${ }^{37}$

garantía hipotecaria, no se trataba específicamente de crédito para la compra de tierra u otros bienes inmuebles. Las operaciones utilizadas tanto para este análisis como para la elaboración del siguiente gráfico consistían en préstamos particulares, cuya garantía estaba dada por hipotecas sobre inmuebles rurales o urbanos. Es verdad que existió otro tipo de mercado hipotecario en el mercado inmobiliario rural de Santa Fe, sobre todo en las colonias, pero en ese caso la financiación se hacía para el pago de la tierra, y no implicaba la entrega de dinero en efectivo. Este tipo de crédito fue muy utilizado por los empresarios de colonias en la enajenación de las parcelas a colonos que en la mayoría de los casos no contaban con capital suficiente al momento de la compra. Con respecto a los flujos de capital de los '80 y su relación con el descenso de la tasa de interés en Europa y Estados Unidos, ver DJENDEREDJIAN, Julio, BEARZOTTI, Silcora MARTIREN, Juan Expansión..., Op. Cit, T. II, Cap. IX.

37. Sobre este tema, vale destacarse el siguiente trabajo FRID, Carina, "Encontrando la clientela. Comerciantes e inmigrantes en el sur de Santa Fe a fines del siglo XIX" en FRID, Carina y BERNASCONI, Alicia (compiladoras) De Europa a las Américas. Dirigentes y liderazgos (1880-1960), Biblos, Buenos Aires, 2006.

Por otro lado, más allá de que aún no conozcamos en detalle los costos y rendimientos de los distintos negocios vinculados a la circulación del dinero en la dinámica economía agrícola que surgía en las colonias durante el último cuarto del siglo XIX, es evidente que las necesidades de capital que exigió la misma, debieron ser suplidas a riesgo propio con creciente eficacia por diversos actores. Entre éstos, ocuparían un lugar destacado no sólo los bancos formalizados sino sobre 
Gráfico No 1 - Promedio de tasa de interés en el mercado de crédito informal de las ciudades de ciudad de Rosario y en el Hinterland de Santa Fe y en las instituciones bancarias de la provincia

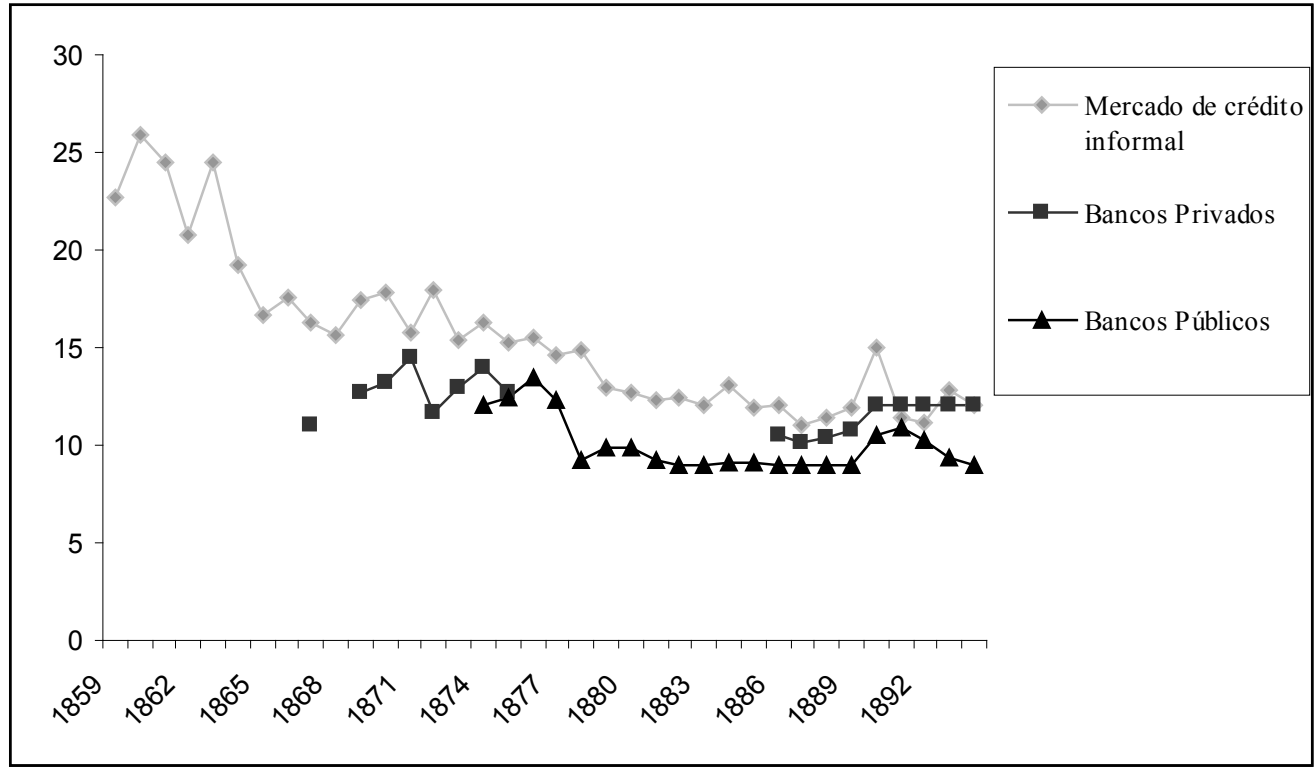

Fuente: Elaboración propia en base a préstamos personales con base hipotecaria registrados ante Escribanos Públicos o Jueces de Paz de la ciudad de Rosario y de la ciudad de Santa Fe y su Hinterland de colonias. Para el caso de Rosario, se elaboraron los índices anuales a partir de un muestreo de 283 operaciones, mientras que para Santa Fe y colonias, la muestra alcanzó las 340 operaciones. Los datos de tasas de interés del mercado bancario fueron extraídos de los diarios $E l$ Ferrocarril y La Capital, ambos editados en la ciudad de Rosario. Se tomó la media aritmética de las tasas mensuales cobradas para los meses en que se contaba con datos. Con excepción de los años 1864 y 1867, donde sólo se consiguieron datos para 4 meses del año, para los demás años se cuenta con datos de un mínimo de 8 meses. 
En otros términos, si la fenomenal expansión agrícola de los años '80 pudo llevarse a cabo, sin duda fue porque logró darse, entre otras cosas, un mercado crediticio lo suficientemente útil, versátil y accesible como para apoyarla, cosa que continuaría haciendo durante las décadas siguientes. ${ }^{38}$ Ambos tipos de crédito, formal e informal, parecían funcionar en forma combinada e integrada; de hecho, es difícil establecer límites entre ambos circuitos, dado que si bien cubrían espacios diferenciales, uno y otro se necesitaban mutuamente.

Este gráfico (ver Gráfico № 1), que mide el costo del dinero durante la mayor parte del período estudiado, es una cabal muestra del nivel de modernización que la economía santafesina alcanzó en el último cuarto de siglo, y del papel del financiamiento durante ese lapso. Puede verse así una tendencia fuertemente decreciente en ambos mercados de crédito. Se pasó de tasas muy altas, que en los años '50 y '60 superaban el $2 \%$ mensual, a alrededor de la mitad, descenso que derivó en una estabilidad bastante sostenida durante la década de 1880 y 1890 , pese a algunas oscilaciones. Los años '70, en este caso, jugaron un rol particular, ya que operaron como bisagra en estos cambios. Así, luego de sentir fuertemente el impacto de la crisis de 1876 , las tasas comenzaron una tendencia a la baja (desde mediados de la década en Rosario y un poco más tardíamente en la zona de Santa $\mathrm{Fe}$ ), que terminaría de consolidarse hacia 1880 , pero que fue previa a ese año, considerado el

todo los comerciantes rurales, agentes últimos de la cadena de oferta de crédito.

38. DJENDEREDJIAN, Julio, BEARZOTTI, Silcora, MARTIREN, Juan, Expansión..., Op. Cit, T. II, Cap. IX. 152 de cambio de tendencia con respecto al flujo de capital externo, por el descenso de las tasas de interés de largo plazo que se verificó desde entonces en las economías centrales.

Queda claro, al igual en el mercado de crédito entre particulares, la baja sostenida de tasas durante los ' 80 tanto en los bancos estatales cuanto en los privados, que se manifestó además, por lo que puede verse, en una competitividad creciente para el sistema formal, que pudo ofrecer tasas más bajas que el informal, y sin dudas con un spread menor entre tasas activas y pasivas, mejorando así la eficiencia general del sistema. Esto parece evidente teniendo en cuenta que la expansión económica atrajo un importante flujo de fondos de capital comercial y financiero que permitió la posibilidad de un financiamiento cada vez más barato para la producción agrícola; a su vez, estos bancos pasaron a nutrir a los acopiadores locales y demás actores del mercado crediticio, quienes conseguían transmitirlo con tasas más bajas a los productores, circulando así por las cada vez más densas redes comerciales de la campaña. De esta manera, ambos mercados de crédito terminaron siendo fundamentales en la modernización económica de la provincia hacia fines de siglo. ${ }^{39}$

\section{Consideraciones finales}

La evolución de la economía santafesina durante el siglo XIX tuvo básicamente cuatro grandes etapas, con características variopintas, que abarcaron tanto momentos de fuertes crisis, como otros de crecimiento sin

39. Un análisis muy detallado sobre el funcionamiento del mercado crediticio en Santa Fe en GALLO, Ezequiel, La Pampa..., Op. Cit., pp. 237 y ss. 
precedentes. Los inicios del siglo posicionaban a Santa Fe como una prominente provincia del Litoral, que se había visto beneficiada, en particular, por los efectos del renacer potosino que desde la década de 1760 venía alimentando a la economía rioplatense. Sin embargo, el impacto de las guerras civiles que derivaron de la independencia sería allí devastador, lo cual desencadenaría por tanto una segunda etapa en el devenir económico de ese siglo. En el decurso de las tres décadas posteriores a la revolución, la provincia sufriría una y otra vez los efectos de saqueos y robo de ganado, invasiones indígenas, quebrantos comerciales y siderales pérdidas económicas.

Ahora bien, ese período crítico comenzó a amainar a fines de los'30 y, al parecer, desde los años '40 la producción ganadera comenzaría un sendero de recuperación, alentada sobre todo por la más dinámica economía del sur provincial, que tenía a la ciudad de Rosario como centro neurálgico. Justamente en ese contexto, la política de expansión de fronteras y el fomento de la colonización agrícola iniciados en la década del '50 marcarían un punto de inflexión en la economía santafesina. $\mathrm{Se}$ producirían progresivas avanzadas en la línea de fortines, adosando a los activos estatales enormes planteles de tierras, que progresivamente serían traspasados al sector privado. Desde luego, no se trató de una tarea fácil: se debió aplicar una significativa planificación para lograr la puesta en producción del espacio y acrecentar el número de operadores en esa economía. Justamente fue en medio de ese proceso cuando comenzó el ciclo de fundación de colonias agrícolas, y pese al lento pero constante ritmo de crecimiento que estas colonias adquirieron, terminaría por plasmarlas como una alternativa viable para incrementar la producción de granos. Ese progresivo desarrollo de la colonización, acompañado por un menor, aunque igualmente sostenido crecimiento de la ganadería, fue posibilitando poco a poco la construcción de bases algo más sólidas para la expansión económica que sobrevendría en la década de 1880. El uso más intensivo de la tierra, propiciado por esa emergente economía farmer, permitió alcanzar inéditos índices de una producción triguera que poco a poco estaba logrando posicionarse como alternativa de abasto a los cereales importados en el mercado nacional, y que incluso desde 1879 se estaba dirigiendo a las plazas transatlánticas.

Los frutos de estas mejoras se verían claramente retratados en la cuarta etapa de la economía santafesina,iniciada en los tempranos años '80. A partir de allí, la maduración del proceso de colonización lo ubicó como la actividad principal del esquema productivo provincial. De este modo, la especialización triguera se volvió fundamental al proveer economías de escala y permitir la emergencia de un mercado nacional de cereales, del cual Santa Fe sería principal protagonista hasta la década de 1890. Ello fomentó una impresionante inversión en dotación de infraestructura de comunicaciones ferroviaria, fluvial y terrestre, de centros de acopio y puertos y de algunos emprendimientos industriales. Se consolidó al mismo tiempo un sistema monetario sólido y la proliferación de bancos modernos permitieron desarrollar un mercado crediticio que impactó muy positivamente en las tasas de financiación, no sólo del mercado de crédito bancario, sino también del informal, que había funcionado en la provincia desde antiguo. En ese ámbito, cobrarían particular relevancia los comerciantes rurales, que se convertirían 
en eslabones fundamentales en la cadena de producción cerealera.

La economía santafesina ya no sería la misma a partir de allí. Tuvo que afrontar, no obstante, los cimbronazos producidos por la crisis de 1890, pero la profundidad de transformaciones alcanzadas ya no se revertiría hasta fines del siglo. Sustentada sobre todo por la consolidación de un proceso de colonización agrícola, que tuvo una influencia fundamental en el éxito del esquema agrícola pampeano, la provincia de Santa Fe se había convertido en la principal potencia triguera del país en tan sólo cuatro décadas.

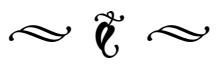

Recibido: 15/04/2014 Aceptado: 08/09/2014 